NASA Technical Memorandum 103606

AIAA-90-4022

\title{
Unsteady Blade Pressure Measurements for the SR-7A Propeller at Cruise Conditions
}

(NASA-TM-103600) UNSTEAOY BLADE PRFSSURE

MEASUREMENTS FOR THE SR-7A PRTPELLER AT

CRUISE CONOITIONS (NASA) $17 \mathrm{P}$ CSCL $20 A$

Na1-19325

L.J. Heidelberg

Lewis Research Center

Cleveland, Ohio

and

M. Nallasamy

Sverdrup Technology, Inc.

Lewis Research Center Group

Brook Park, Ohio

Prepared for the

13th Aeroacoustics Conference

sponsored by the American Institute of Aeronautics and Astronautics

Tallahassee, Florida, October 22-24, 1990 


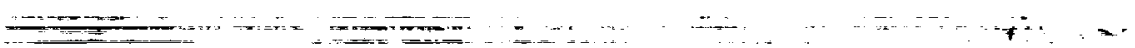


UNSTEADY BLADE PRESSURE MEASUREMENTS FOR THE SR-7A PROPELLER

\title{
AT CRUISE CONDITIONS
}

\author{
L.J. He idelberg \\ National Administration and Space Administration \\ Lewis Research Center \\ Cleveland, Ohio 44135-3191
}

and

M. Nal lasamy

Sverdrup Technology, Inc.

Lewis Research Center Group

Brook Park, Ohio 44142

\section{SUMMARY}

The unsteady blade surface pressures were measured on the SR-7A propeller. The freestream Mach number, inflow angle, and advance ratio were varied while measurements were made at nine blade stations. At a freestream Mach number of 0.8 , the data in terms of unsteady pressure coefficient versus azimuth angle is compared to an unsteady three-dimensional Euler solution. This comparison of waveforms with the code yielded very encouraging results. The code predicts the shape (phase) of the waveform very well while the magnitude is overpredicted in many cases. At tunnel Mach numbers below 0.6 , an unusually large response on the suction surface at 0.15 chord and 0.88 radius was observed. The behavior of this response suggests the presence of a leading edge vortex. The midchord measuring stations on the suction surface exhibit a response that leads the forcing function while most other locations show a phase lag. Evidence of trailing edge shocks crossing the blade passage and impinging on the pressure surface of the following blade was found at tunnel Mach number of 0.85 .

\section{INTRODUCTION}

In order to achieve the substantial fuel savings of fered by an advanced turboprop over turbofan engines, cabin and community noise levels must be acceptable. The noise caused by unsteady loading of the blades can be significant source for single rotation propellers. This is the case where the axis of rotation is at angle to the inflow or where there is a distortion of the inflow caused by installation effects. The sensitivity of a single rotation propeller to inflow angle was shown to be between 0.8 to $1.6 \mathrm{~dB}$ per degree of inflow angle change in the $f$ light test reported in reference 1 .

In this investigation the unsteady blade surface pressures were measured on the SR-7A propeller which is a $2 / 9$ aeroelastic scale model of the "LargeScale Advanced Propfan" (LAP) propeller. The flight Mach number, inflow angle, and advance ratio were varied while measurements were made at nine blade stations. The limitations of scale, and the number of data channels that could be brought across the rotating interface, limited the number of measuring stations. 
At a freestream Mach number of 0.8 , the data are compared to an unsteady three-dimensional Euler solution. The solution procedures were developed by Whitfield, et al. (refs. 2 and 3 ). The solution for an inflow angle of $1.6^{\circ}$ was reported by Nallasamy (ref. 4).

\section{APPARATUS AND PROCEDURES}

The tests were conducted in the NASA Lewis 8- by 6-Foot Supersonic Wind Tunnel over a range of Mach numbers from 0.4 to 0.85 . Figure 1 shows the SR-7A propeller installed in the tunnel. The inflow angle was varied by pitching the propeller axis up. The pitch angle (inflow angle) was varied from $-1^{\circ}$ to $4^{\circ}$. Most of the data were obtained at an advance ratio, J, of 3.06 , while limited data were obtained at $J=2.9$ and $J=3.2$. The blade setting angle for the tests was $60.1^{\circ}$. The cruise design parameters for this propeller are presented in table $I$.

\section{Blade Mounted Transducers (BMT's)}

Ten miniature pressure transducers were mounted on two different blades in positions shown in figure $2(\mathrm{a})$. Two chordwise stations were used at both the $0.75 R$ and $0.88 R$ ( $R=$ radius $)$, while only the $0.1 C(C=$ chord) station was used at $0.65 \mathrm{R}$. The BMT's measuring the suction surface were all mounted on one blade while the pressure surface measurements were made on a second blade. The two instrumented blades were mounted in the hub $180^{\circ}$ apart. The transducers were mounted to measure the pressure through a $1.55 \mathrm{~mm}$ diameter hole drilled through the blade as shown in figure 2(b). An RTV silicone adhesive was used for bonding in order to ensure that the transducers were strain isolated from the blade. The RTV adhesive was also used to fair the BMT in to the blade surface.

The signals from the BMT's are taken of $f$ the rotor through a rotary transformer. Transducer excitation is a $30 \mathrm{kHz}$ signal brought across the rotary transformer. The transducer output amplitude modulates the $30 \mathrm{kHz}$ carrier which is demodulated, amplified, and recorded on FM tape. The system frequency response was $10 \mathrm{kHz}$ or 65 to 130 shaft orders (P orders) depending on rpm.

The recorded BMT signals, along with the once-per-revolution pulse were digitized at rate of 128 samples per revolution. The digital information was then processed on a mainframe computer to produce 100 time ensembles of ten revolutions each. These were averaged synchronously to the once-per revolution pulse (time domain averaging), and fast Fourier transforms (FFT's) were taken to produce enhanced spectra and phase (azimuth) angles. In addition, FFT's were taken of the individual time ensembles of data and then averaged in the frequency domain. These spectra were only used to monitor data quality. The broadband level provided by the frequency domain average allows a check on amplifier gains, transducer health, and sets a lower limit to which the tone levels can be enhanced. All spectra produced are in terms of shaft orders (P). 


\section{RESULTS AND DISCUSSIONS}

Measurements were obtained for 9 blade stations (one station on the pressure surface at $0.1 \mathrm{C}$ and $0.75 \mathrm{R}$ was not functioning). The following parameters were varied over the stated ranges: tunnel Mach number, $M_{\infty}=0.4$ to 0.85 ; inf low angle, $\propto=-1^{\circ}$ to $4^{\circ}$; advance ratio, $\mathrm{J}=2.9$ to 3.2 .

\section{Typical Response to Angular Inflow}

All the data presented has been averaged in the time domain synchronous to the once-per-revolution signal. The waveform (pressure versus azimuth angle) and spectrum for the suction surface at the $0.1 \mathrm{C}, 0.65 \mathrm{R}$ location for an inflow angle of $1.5^{\circ}$ and $M_{\infty}=0.8$ is shown in figure 3 . All the results presented have been corrected for the residual signal at zero inflow angle. It was found that when the propeller was set at a $0^{\circ}$ pitch angle in the tunnel there was still significant variation in the transducer signals with azimuth angle for some of the data channels. Most of this variation was at the first shaft order. It is thought that this was a result of imperfections in the windings of the rotary transformer used to $t r a n s f e r$ the signals from the rotating propeller, and some residual angular inflow. To correct for this, the first shaft order signal at zero indicated inflow angle was subtracted from the signals at all inflow angles. The reference for the azimuth angle used here is shown in figure 4 where $0^{\circ}$ is at the top and the angle is measured in the direction of rotation (clockwise looking downstream). Thus, the maximum blade angle of attack occurs near $90^{\circ}$ and the minimum near $270^{\circ}$ for a positive (pitch up) inflow angle. Figure $3(\mathrm{a})$ shows that the minimum pressure occurs somewhat later than the $90^{\circ}$ position that corresponds to the maximum blade angle of attack. The phase lag here is $26.8^{\circ}$. The spectrum shown in figure $3(\mathrm{~b})$ is the Fourier transform of figure $3(\mathrm{a})$. The first shaf $t$ order is by far the dominant signal with the second shaft order almost an order of magnitude lower.

\section{Comparison with Unsteady Three-dimensional Euler Solution}

The unsteady three-dimensional Euler solutions at three inflow angles for the full-scale version (SR-7L) of the propeller tested here were presented in reference 4. The comparison between the Euler solution and the data will be made at individual measuring stations in terms of the unsteady pressure coefficient and azimuth angle (waveform). This is a most detailed and stringent kind of comparison. The unsteady pressure coefficient used here is the value of the unsteady pressure divided by the local dynamic pressure. Dynamic pressure was calculated from the tunnel static pressure and the vector sum of the tangential and axial velocities at the local blade radius. Some of the code conditions were slightly different than the data. The blade station locations for the code are within 2.9 percent of chord or radius of the measurement locations. The code was run at an advance ratio of 3.12 while the data was taken at $J=3.06$. The inflow angle for the code was $1.6^{\circ}$ while the data was at $1.5^{\circ}$. The blade setting angle for the code was $58.4^{\circ}$ while the data was taken at $60.1^{\circ}$.

Comparison of the code results to the measured waveforms for the pressure surface locations are shown in figure 5 . The stations at $0.1 \mathrm{C}$ for both the $0.65 \mathrm{R}$ and $0.75 \mathrm{R}$ (figs. $5(\mathrm{a})$ and (b)) show excellent agreement between the data 
and code results. For the $0.5 \mathrm{C}$ and $0.88 \mathrm{R}$ station ( $\mathrm{fig} .5(\mathrm{~d})$ ) the code overpredicts the magnitude but is in good agreement with the data in phase angle. At the $0.15 \mathrm{C}$ and $0.88 \mathrm{R}$ station (fig. $5(\mathrm{c})$ ) there are substantial differences between the code predictions and data. These differences involved both the shape and magnitude of the waveform. When the next higher inflow angle data $\left(\propto=2.0^{\circ}\right)$ is overlaid on the figure it can be seen there is a large change in waveform shape and magnitude for the $0.5^{\circ}$ increase in inflow angle. This and the fact that the waveform is not sinusoidal may be an indication that an unusual flow phenomenon is involved at this location and operating condition. It is interesting to note that the code results are in closer agreement with the $2^{\circ}$ data.

The comparisons for the suction surface stations are shown in $f$ igure 6 . The 0.1 chord stations at $0.65 R$ and $0.75 R$ (figs. 6(a) and (b)) are somewhat overpredicted in magnitude but show good agreement in phase angle. The $0.5 \mathrm{C}$, $0.75 \mathrm{R}$ (fig. $6(\mathrm{c})$ ) shows similar results to the $0.1 \mathrm{C}$ stations. At the $0.15 \mathrm{C}$, $0.88 \mathrm{R}$ station (fig. $6(\mathrm{~d})$ ) the data for the $1.5^{\circ}$ inflow angle was not available. Because of this the data at the next lower and higher inflow angles are shown $\left(1.0^{\circ}\right.$ and $\left.2.0^{\circ}\right)$. Consistent with the code overpredicting the pressure coefficient magnitude the $2.0^{\circ}$ data is in good agreement with the code prediction for $1.6^{\circ}$ inflow angle. Finally, the $0.5 \mathrm{C}, 0.88 \mathrm{R}$ station shown in $\mathrm{fig}-$ ure 6(e) shows the same overprediction in magnitude and good agreement in phase as was the case for many of the previous comparisons.

\section{Effect of Inflow Angle}

The effect of inflow angle on the unsteady pressure coefficient at the first shaft order, $C_{P_{1}}$, can be seen in figures 7 to 9 . Both the magnitude and phase are shown. The magnitude of $C_{P 1}$ is the rms value of the unsteady pressure at the first shaft order divided by the local dynamic pressure. The phase angles reported here are in terms of lead or lag from the forcing function. For a suction surface, the forcing function is considered to be negative when the blade angle of attack is positive, while the pressure surface forcing function would be positive. Figure 7 shows the inflow angle effect on $C_{P 1}$ at a Mach number of 0.4 for all nine locations. The magnitude of $\mathrm{C}_{\mathrm{P} 1}$ on the pressure surface at the stations near the leading edge have a linear response to inflow angle. The midchord stations show some nonlinear tendencies. The phase angles for all stations are similar in value $\left(20^{\circ}\right.$ to $\left.35^{\circ} \mathrm{lag}\right)$ and seem unaffected by inflow angle. On the suction surface the value of $C_{P 1}$ for $0.15 \mathrm{C}$ and $0.88 \mathrm{R}$ has a response of more than four times (see the alternate scale on the right) the other leading edge stations and is nonlinear. This unusual behavior is a function of Mach number and will be discussed later. The midchord stations show lower but more linear response. The phase angle for both midchord stations show a lead while, the leading edge stations show a phase lag. Except for the $0.15 \mathrm{C}, 0.88 \mathrm{R}$ station, and $0.5 \mathrm{C}, 0.88 \mathrm{R}$, the phase angle does not change with inflow angle.

Figure 8 presents the response of all stations to inflow angle at the Mach number of 0.6 . The response on the pressure surface are almost the same as the $\mathrm{K}_{\infty}=0.4$ results for both $\mathrm{CP}_{1}$ and phase angle. On the suction surface (see Fig. $8(b)$ ), the magnitudes of $C_{P 1}$ are similar to the $M_{\infty}=0.4$ results, except for the $0.15 \mathrm{C}, 0.88 \mathrm{R}$ station which shows a large decrease. The phase of the two midchord stations show less lead, than at $M_{\infty}=0.4$. This is particularly true for the $0.88 \mathrm{R}$ station. 
Finally, the response at $M_{\infty}=0.8$ is shown in figure 9 . The pressure surface $C_{P 1}$ magnitudes of the leading edge stations are slightly reduced from the $M_{\infty}=0.6$ case while the midchord stations are somewhat higher. They all exhibit a linear relation with inflow angle. The phase angles here again show little change with inflow angle except for the $2^{\circ}$ inflow case at $0.15 \mathrm{C}, 0.88 \mathrm{R}$ where there is a sudden increase in lag. This is a result of a.new feature in the waveform and will be discussed later. The magnitude of the $\mathrm{C}_{\mathrm{P} 1}$ on the suction surface is similar to that of the $M_{\infty}=0.6$ data except for a lower response to inflow angle. The phase angle still shows very small change with inflow angle but the $0.5 \mathrm{C}, 0.88 \mathrm{R}$ station no longer leads the forcing function. It should be noted that as the Mach number was increased the maximum inflow angle that could be run was decreased due to blade stress.

\section{Effect of Mach Number}

Data were taken between $M_{\infty}=0.4$ and 0.85 in 0.05 increments. The unsteady pressure coefficient at the first shaft order, $\mathrm{C}_{\mathrm{P}_{1}}$ is plotted against the blade section relative Mach number, $M_{r}$ at $J=3.06$ and inflow angle, $\alpha=2^{\circ}$ in figures 10 and 11 . The magnitude and phase of $\mathrm{Cp}_{1}$ for the pressure surface station is shown in figure 10 . The magnitude of the $0.65 \mathrm{R}$ and $0.75 \mathrm{R}$ stations decreases above a relative Mach number of 0.95 , while both $0.88 \mathrm{R}$ stations show a general trend of increasing $M_{r}$. The $0.5 \mathrm{C}, 0.88 \mathrm{R}$ station has a dramatic increase above $M_{r}=1.1$. There is a complete change in waveform, possibly due to a shockwave from the trailing edge of blade just ahead. The waveforms for this and other unusual effects will be shown in a later section. The phase angles of the leading edge stations have a gradual decrease with increasing $M_{r}$. The midchord stations show little change in phase angle except above $M_{r}=1.1$, where there is a sudden increase in lag corresponding to the wavef orm change.

The suction surface response to $M_{r}$ is shown in figure 11 . Here the most obvious feature is the high and rapidly decreasing response with increasing $M_{r}$ of the $0.15 \mathrm{C}, 0.88 \mathrm{R}$ station. The reason for this high response is not known but may be caused by a leading edge vortex. This kind of high and rapidly changing response has been seen on this propeller before at takeof $f$ conditions (ref. 5). It was not expected that a leading edge vortex would play any role at cruise conditions. The other two leading edge stations have very similar response to each other with $C_{P 1}$ in the 0.06 range up to $M_{r}=0.95$ then decreasing at higher $M_{r}$. The phase response to $M_{r}$ for the three leading edge stations is similar, with increasing lag with $M_{r}$. The midchord stations have phase leads at low Mach numbers with the lead decreasing with increasing $M_{r}$. The $0.5 \mathrm{C}, 0.88 \mathrm{R}$ station decreases its lead angle with increasing $M_{r}$ to the point that it turns into a lag above $\mathbb{M}_{\mathrm{r}}=0.85$.

\section{Effect of Advance Ratio}

The effect of advance ratio, $J$ on the unsteady pressure coefficient at the first shaft order $C_{P 1}$ is shown in figures 12 and 13 for $M_{\infty}=0.6$ and $M_{\infty}=0.8$, respectively. Advance ratio is def ined here as $J=V_{\infty} / n D$ where $n$ is the rotational speed and $D$ is the tip diameter. Both the magnitude and the phase of $C_{P 1}$ are shown at an inflow angle of $2^{\circ}$. Only three advance ratios were run, $2.90,3.06$, and 3.20 . 
The pressure surface stations at $M_{\infty}=0.6$ are shown in figure $12(a)$. There are no significant trends at these stations al though there is a tendency for the pressure coefficient magnitude to increase slightly with $J$. On the suction surface there is more activity as shown in figure $12(\mathrm{~b})$. The $0.15 \mathrm{C}$, $0.88 \mathrm{R}$ station there is a large decrease with increasing J. This is the same location that exhibited very high levels of $C_{P_{1}}$ that decreased rapidly with increasing $M_{\infty}$ as discussed in the previous section. This decrease in response with steady blade loading (increasing $J$ ) is consistent with a leading edge vortex. The other stations show no strong trends in $\mathrm{C}_{P_{1}}$ with J. With the exception of the $0.5 \mathrm{C}, 0.88 \mathrm{R}$ station which goes from a substantial phase lead at $J=2.9$ to a near zero phase angle at $J=3.2$; there are only small changes in phase angles with $\mathrm{J}$.

The effect of $J$ on the pressure surface measuring stations at $M_{\infty}=0.8$ is shown in figure 13(a). There is a general trend for the magnitude of the pressure coefficient to decrease with increasing J. This is different from the $M_{\infty}=0.6$ data where there was a slight increase with $J$. The only large change in phase angle occurs at the $0.15 \mathrm{C}, 0.88 \mathrm{R}$ station where there is a decrease in lag as $J$ increases. The suction surface data are shown in $f$ igure $13(\mathrm{~b})$ for $M_{\infty}=0.8$. There are not any significant trends in either the magnitude or phase of the pressure coefficient with J. Unfortunately, the $0.15 \mathrm{C}, 0.88 \mathrm{R}$ station data is unavailable here.

\section{Selected Waveforms of Unusual Effects}

Examination of the waveforms at conditions where unusual response is noticed can lead to a better understanding of the phenomena responsible.

The unusually high response of the $0.15 \mathrm{C}, 0.88 \mathrm{R}$ station on the suction surface at low Mach numbers is examined further in figure 14 . Here the waveforms in terms of $C_{p}$ as a function of azimuth angle is shown for $M_{\infty}=0.4$, $0.5,0.6$, and 0.7 at $\propto=2^{\circ}$. At $M_{\infty}=0.4$, the positive (minimum loading) part of the waveform has a sawtooth shape with a rapid drop past $340^{\circ}$. The zero crossings are over $180^{\circ}$ apart. At $M_{\infty}=0.5$ the levels of $C_{p}$ are lower but with a similar sawtooth shape on the positive side of the axis. The peak has moved to a higher angle and the zero crossings are less than $180^{\circ}$ apart (time spent below the axis is less). For $M_{\infty}=0.6$ there is a large change in the shape. The sawtooth shape with the rapid drop is gone and the zero crossings are much closer together. When the $M_{\infty}$ is raised to 0.7 there is again another major change in shape. The zero crossings here now move in the opposite direction, over $200^{\circ}$ apart (more time spent below the axis). As has been pointed out earlier, the magnitude of $C_{p}$ decreases rapidly with increasing $M_{\infty}$. Nothing definitive can be said as to the source of these waveforms and the evolution with $M_{\infty}$, but similarity has been noticed with waveforms taken at $M_{\infty}=0.2$ at takeoff conditions, where a leading edge vortex seems to be present. These similarities involve the sawtooth shape above the zero pressure axis and the reduced time spent below the axis.

Another unusual area in the data is the change on the pressure surface at midchord and $0.88 \mathrm{R}$ station that occurs between $M_{\infty}=0.8$ and 0.85 at $\propto=2^{\circ}$. Figure 15 shows a comparison of the two waveforms. The $M_{\infty}=0.8$ curve is basically a sinewave with a maximum value near $120^{\circ}$. Examination of the $\mathrm{M}_{\infty}=0.85$ waveform reveals much of $i t$ is parallel to the $M_{\infty}=0.8$ curve. Only at two locations are there big differences: the first starting near $90^{\circ}$ where 
there is a rapid pressure $r$ ise and the second near $330^{\circ}$ with and equally steep pressure drop. The rapid changes in pressure that created this waveform suggest a shock was involved. The unsteady Euler analysis presented in ref. 4 shows that the trailing edge shock crosses the blade passage and impinges on the pressure surface in the vicinity of midchord. Between the waveform shape and the Euler analysis it seem likely that oscillation of the trailing edge shock of the blade just ahead is responsible for the pressure response shown.

\section{CONCLUDING REMARKS}

The surface pressure response to inflow angle of the SR-7A propeller was measured at nine blade locations for Mach numbers in the cruise range. A comparison of the waveforms (unsteady pressure coefficient versus azimuth angle) to an unsteady Euler solution yielded very encouraging results considering the detailed nature of this comparison.

The code predicts the shape (phase) of the waveform very well while the magnitude is overpredicted in many cases. However, only at one measuring sta$t$ ion, $0.15 \mathrm{C}, 0.88 \mathrm{R}$ on the pressure surface was there a substantial difference between the code and the data. This measuring station exhibited rapid changes in waveform with inflow angle and nonsinusodial waveforms. This behavior could be indicative of a flow phenomenon not accounted for in the code.

An unusually large response on the suction surface at 0.15 chord and 0.88 radius was observed. This response decreased rapidly as the Mach number was increased. This response also decreased with decreased loading (increasing J). A leading edge vortex is a possible cause of this behavior.

The midchord measuring stations on the suction surface exhibit a response that leads the forcing function while most other locations show a phase lag.

Evidence of trailing edge shocks crossing the blade passage and impinging on the pressure surface of the following blade was found at tunnel Mach number of 0.85 .

\section{REFERENCES}

1. Bartel, H.W.; and Swift, G.: Near-Field Acoustic Characteristics of a Single-Rotor Propfan. AIAA Paper 89-1055, Apr. 1989.

2. Whitfield, D.L., et al.: Three-Dimensional Unsteady Euler Solutions for Propfans and Counter-Rotating Propfans in Transonic Flow. AIAA Paper 87-1197, June 1987.

3. Janus, J.M., and whitfield, D.L.: A Simple Time Accurate Turbomachinery Algorithm with Numerical Solutions of Uneven Blade Count Configuration. AIAA Paper 89-0206, Jan. 1989. 
4. Nallasamy, M., and Groeneweg, J.F.: Unsteady Euler Analys is of the Flowfield of a Propfan at an Angle of Attack. AIAA Paper 90-0339, Jan. 1990 (Also, NASA TM-102426).

5. Heidelberg, L.J.; and Woodward, R.P.: Advanced Turboprop Wing Installation Effects Measured by Unsteady Blade Pressure and Noise. AIAA Paper 87-2719, Oct. 1987 (Also, NASA TM-100200).

TABLE I. - UNSTEADY BLADE PRESSURE MEASUREMENTS FOR THE SR-7A PROPELLER AT CRUISE CONDITIONS

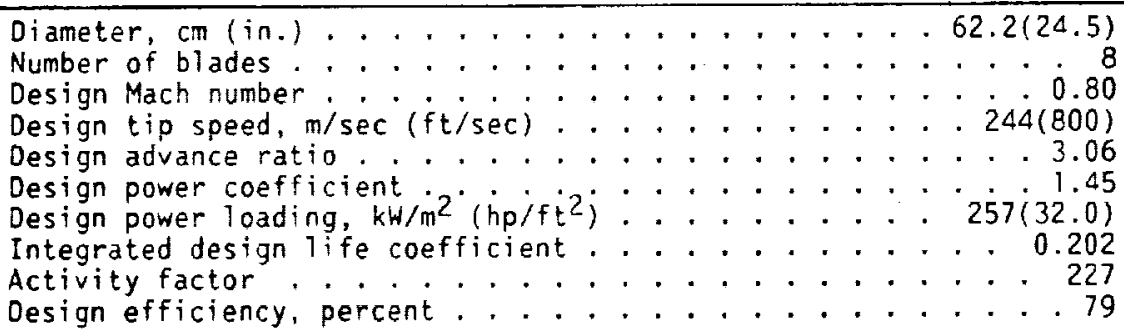

GRIGINAL PAGE

BLACK AND WHITE PHOTOGRAPH

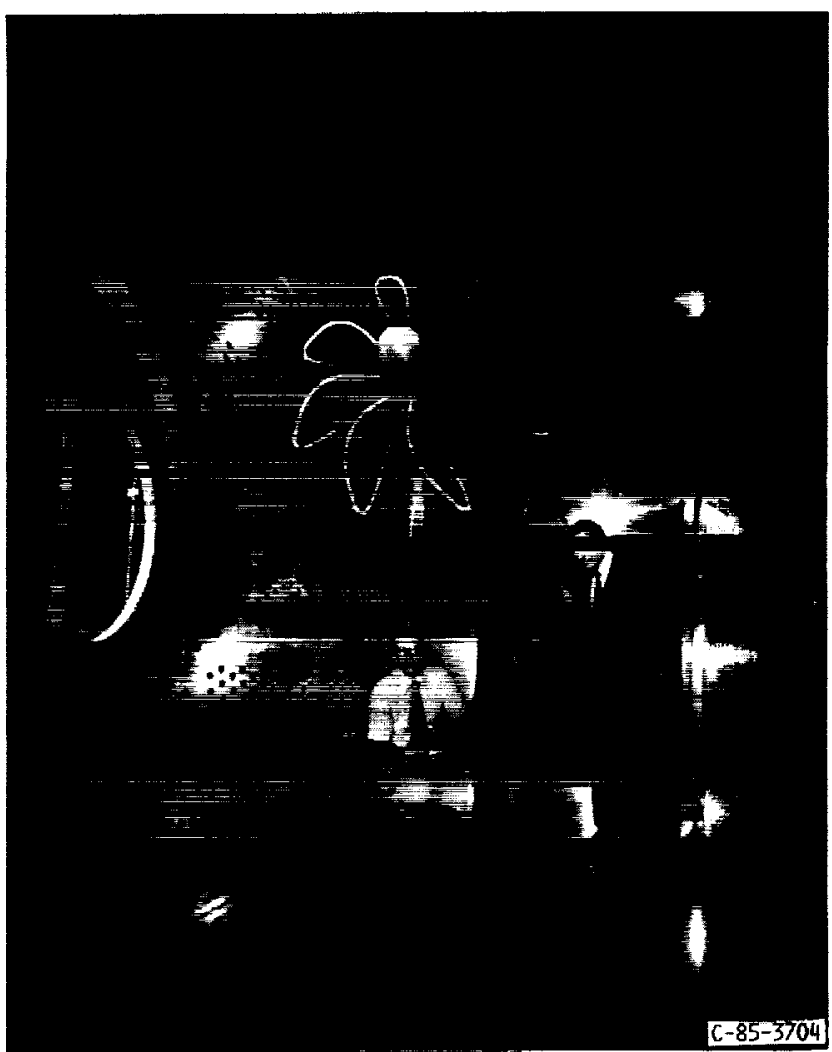

FIGURE 1. - SR-7A PROPELLER INSTALLED IN LEWIS 8- BY 6-FOOT WIND TUNNEL. 


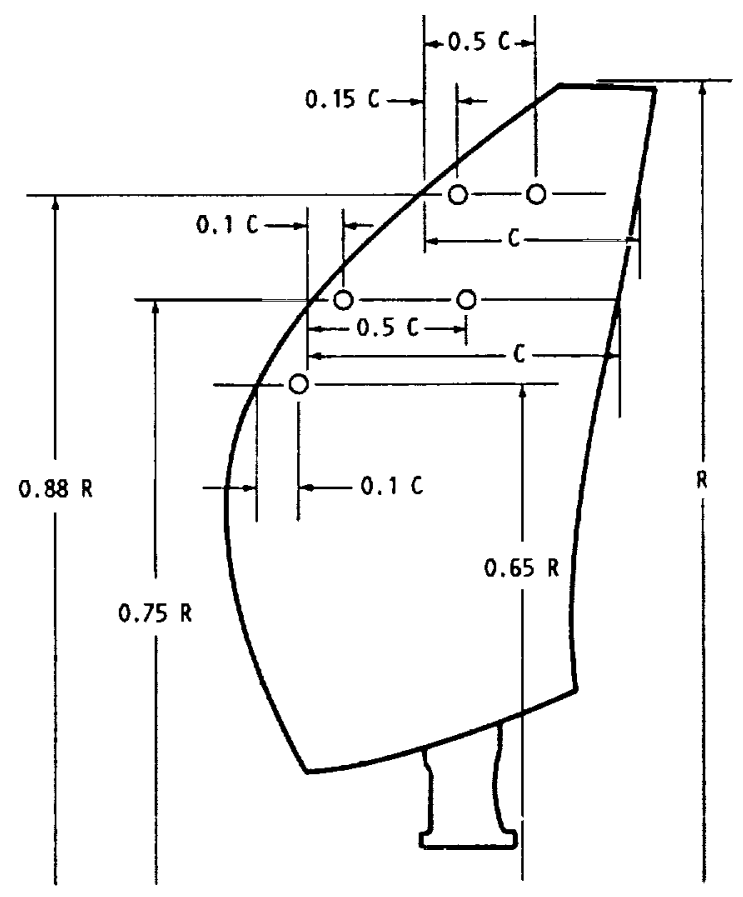

(A) PRESSURE TRANSDUCER LOCATIONS: TWO BLADES INSTRUHENTED. ONE ON PRESSURE SURFACE. THE OTHER ON SUCTION SURFACE.

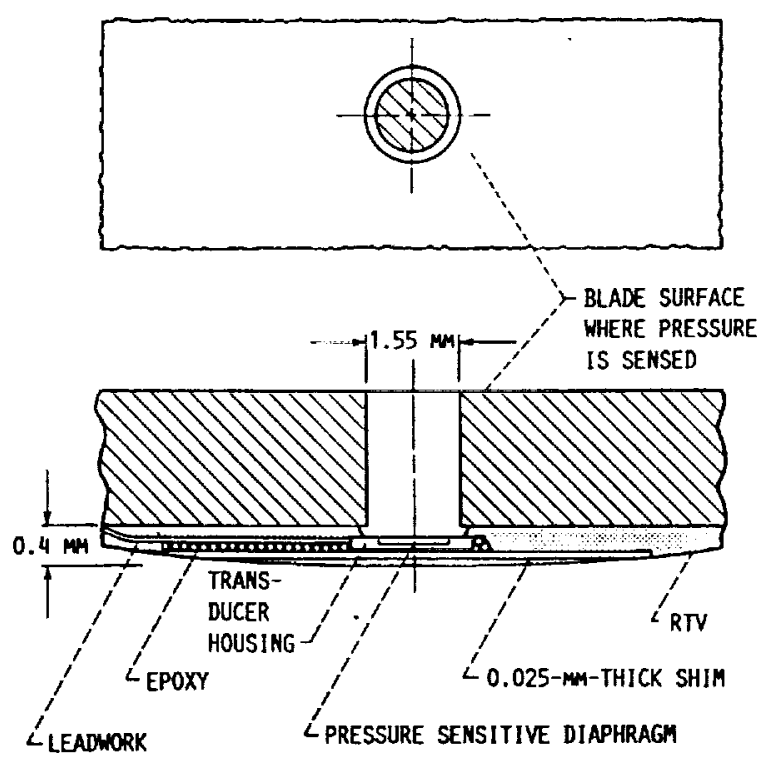

(B) TYPICAL INSTALLATIOH OF BLADE MOUNTED PRESSURE TRANSDUCER SENSING THROUGH BLADE.

FIGURE 2. - BLADE MOUNTED PRESSURE INSTRUIEENTATION.

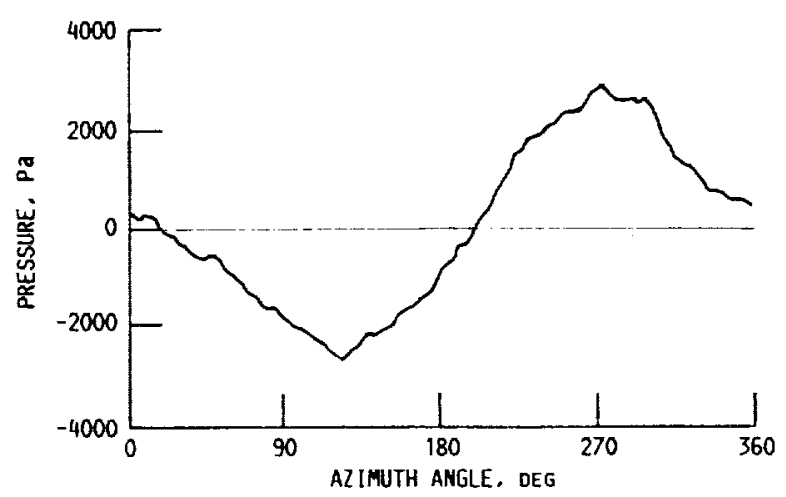

(a) TINE DOMAIN AVERAGED haVEFORM, 100 AVERAGES.

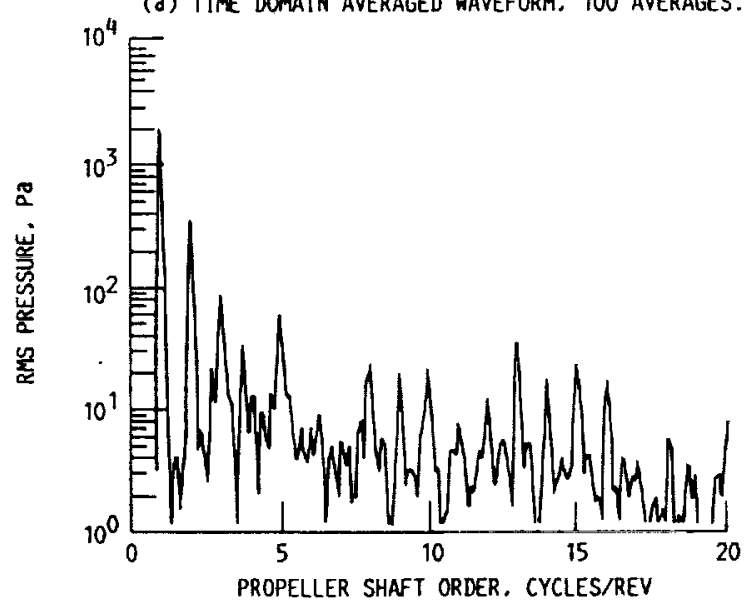

(b) SPECTRUM OF AVERAGE WAVEFORM.

FIGURE 3. - TYPICAL WAVEFORM AND SPECTRUM OF BLADE MOUNTED TRANSDUCER. LOCATION: $0.1 \mathrm{C}: 0.65 \mathrm{~S}$; SUCTION SURFACE. $M_{\infty}=0.8, a=1,5^{\circ}, \mathrm{J}=3.06$.

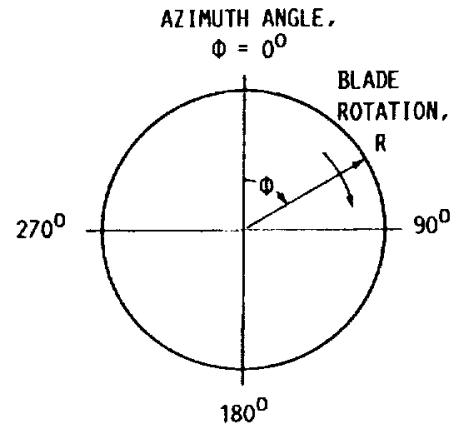

VIEW LOOKING DOWNSTREAM

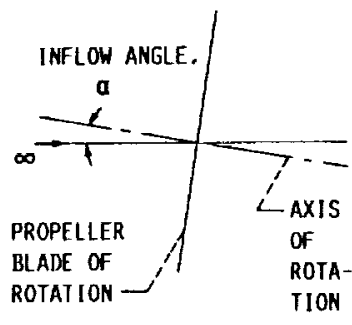

SIDE VIEW
FIGURE 4. - REFERENCE GEOMETRY FOR AZIMUTH AND INFLOW ANGLES. 

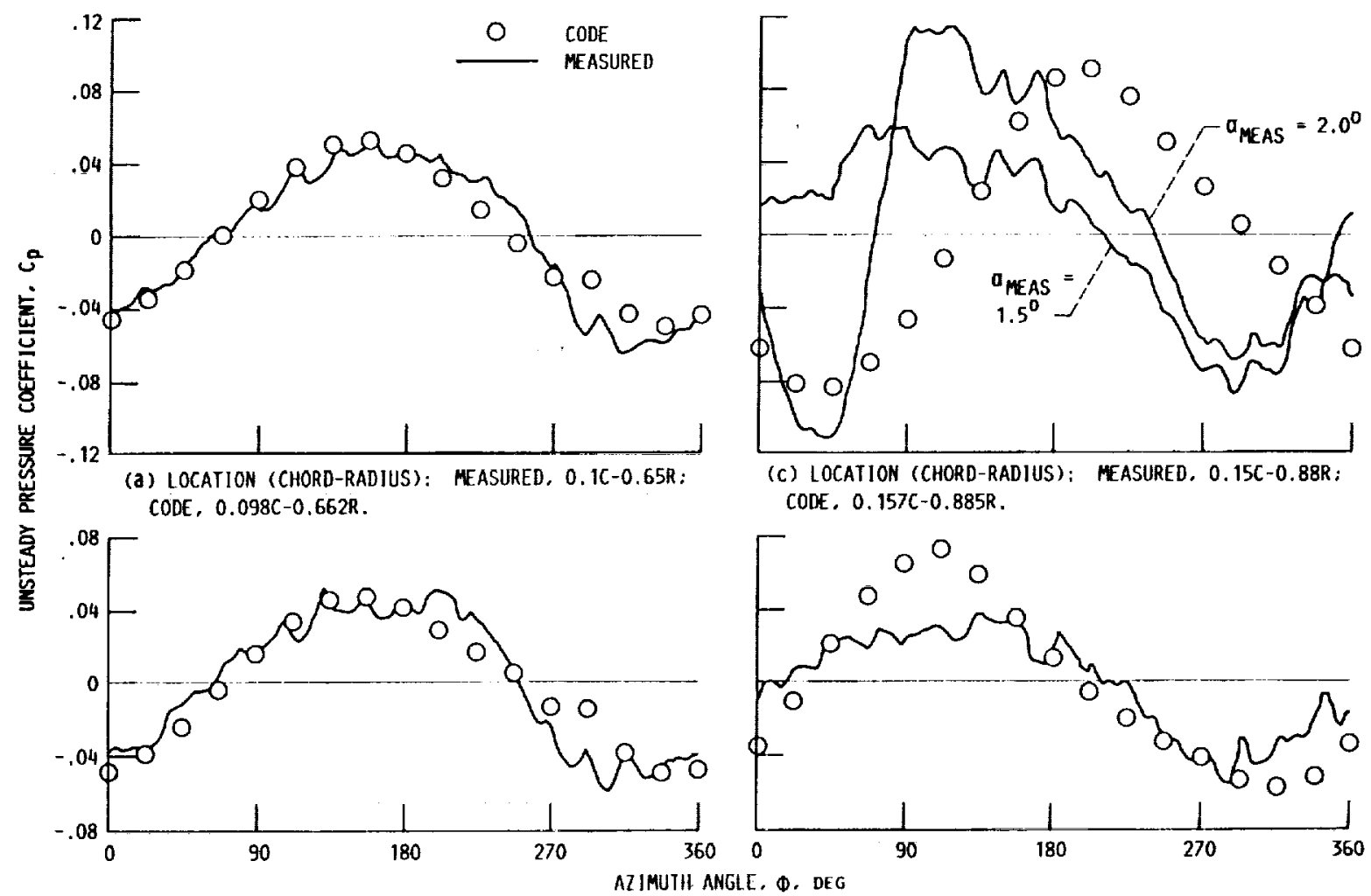

(c) LOCATION (CHORD-RADIUS); MEASURED, 0.15C-0.88R: CODE. $0.157 C-0.885 R$.

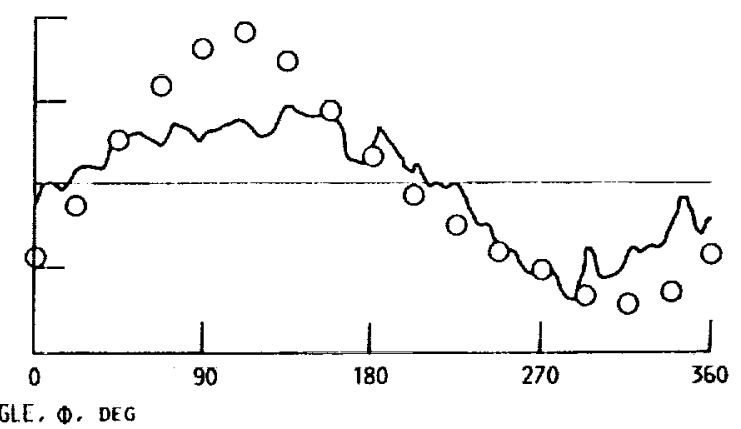

(b) LOCATION (CHORD-RADIUS): MEASURED, 0.1C-0,75R; CODE. $0.098 \mathrm{C}-0.736 \mathrm{R}$.

(d) LOCATION (CHORD-RADIUS): MEASURED, $0.5 C-0.88 R$; CODE, $0.529 \mathrm{C}-0.885 R$.

FIGURE 5. - COMPARISON OF MEASURED WAVEFORMS WITH EUIER CODE SOIUTION ON THE PRESSURE SURFACE. M $=0.8:$ JMEAS $=$ 3.06: $\mathrm{J}_{\text {CODE }}=3.12: a_{\text {MEAS }}=1.5^{\circ}($ EXCEPT AS NOTED $) ; a_{\text {CODE }}=1.6^{\circ}$. 

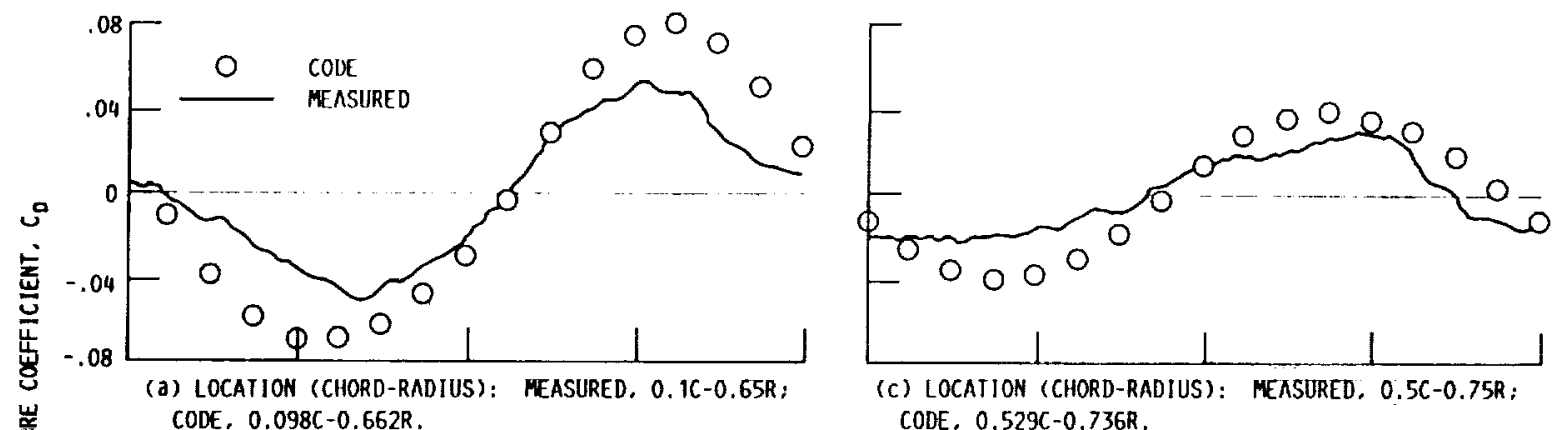
CODE, $0.098 \mathrm{C}-0.662 \mathrm{R}$.
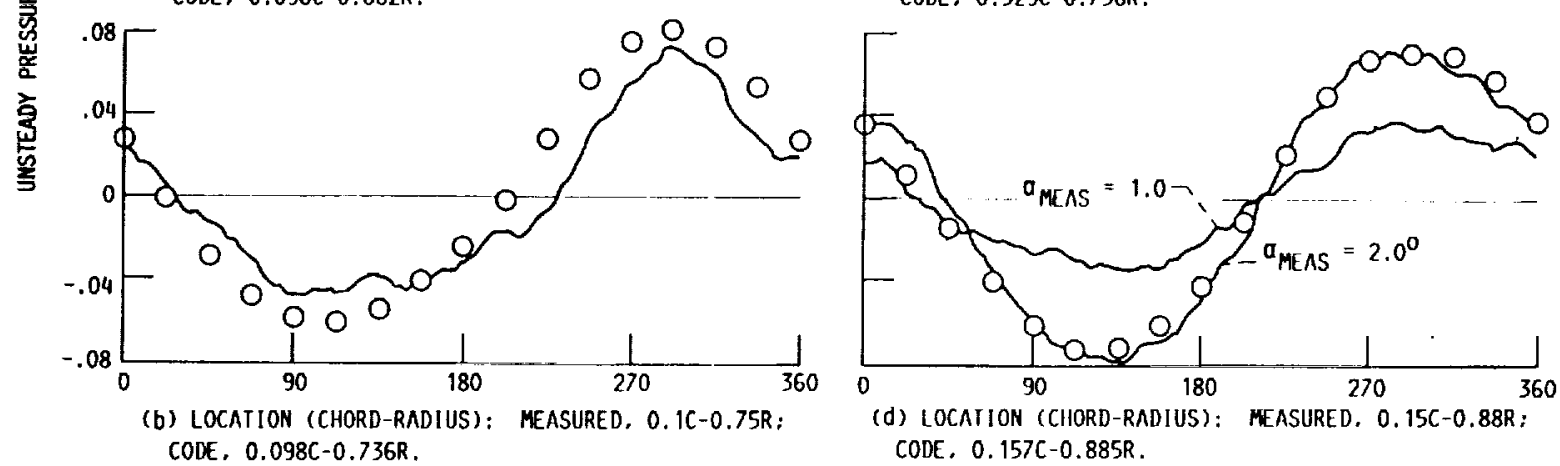

(d) LOCATION (CHORD-RADIUS): CODE, $0.157 C-0.885 R$.

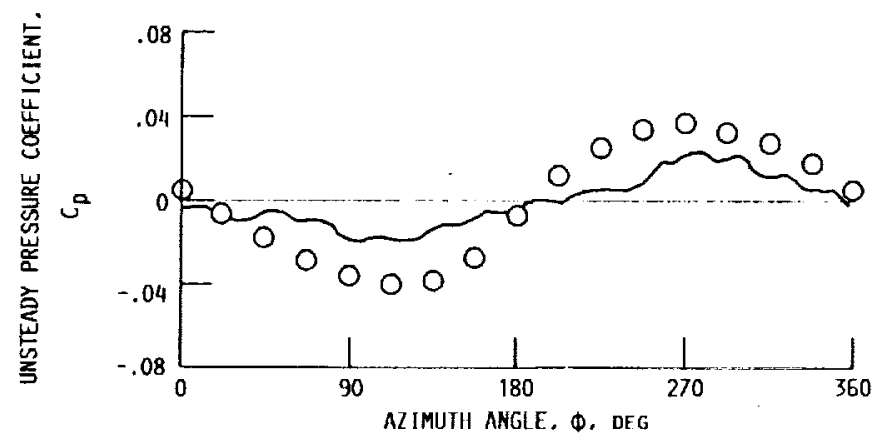

(e) LOCAIION (CHORD-RADIUS); MEASURED, 0.5C-0.88R ;

CODE, 0.529C-0.885R.

FIGURE 6. - COMPARISON OF MCASIIRED WAVETORMS WITH EUIER CODE SOLUTION ON THE SUCTION SURTACT. M -0.8 : JMEAS $=$ $3.06 ; \mathrm{J}_{\text {CODE }}=3.12 ; a_{\text {MEAS }}=1.5^{\circ}$ (EXCEPI AS NOIED); $a_{\text {CODE }}=1.6^{\circ}$. 

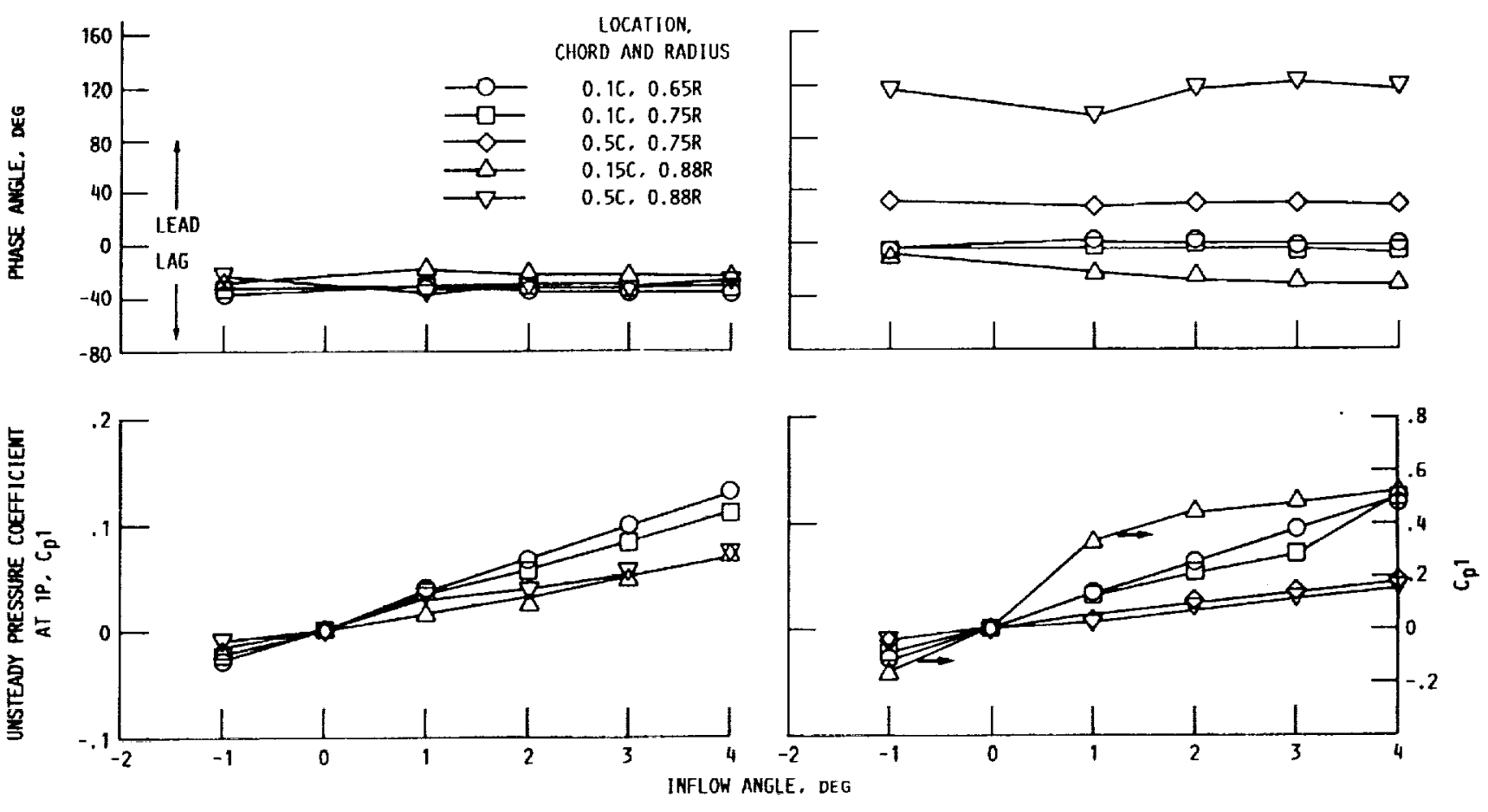

(a) PRESSUIRE SURFACE.

(b) SUCTION SURFACE.

FIGURE 7 . - PRESSURE RESPONSE AS A FURCTION OF INFLOW ANGLE AT $m_{\infty}=0.4$. JMEAS $=3.06$.

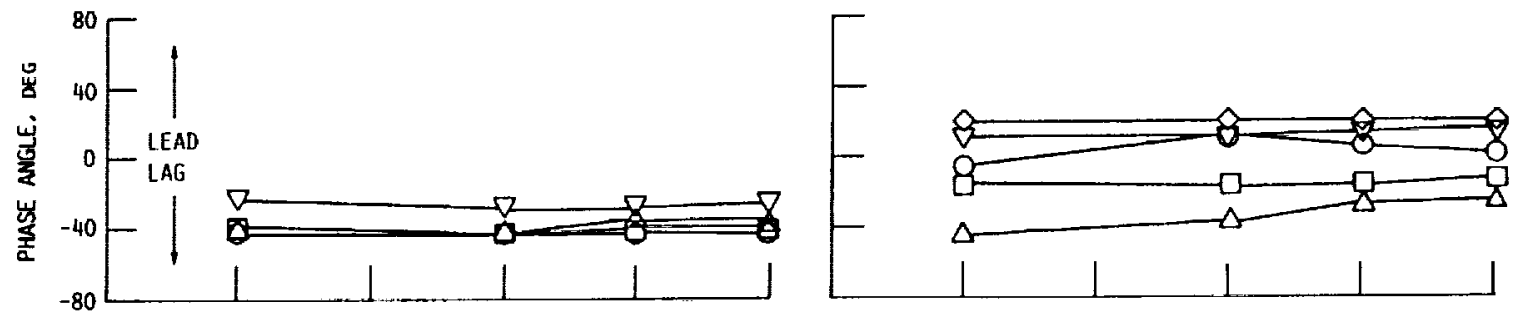

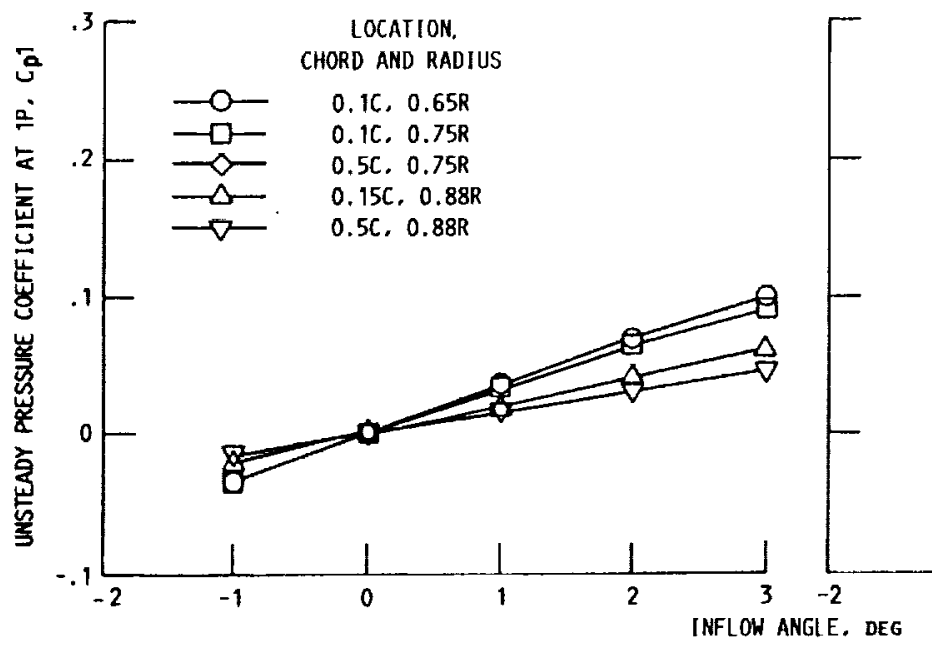

(a) PRESSURE SURFACE,

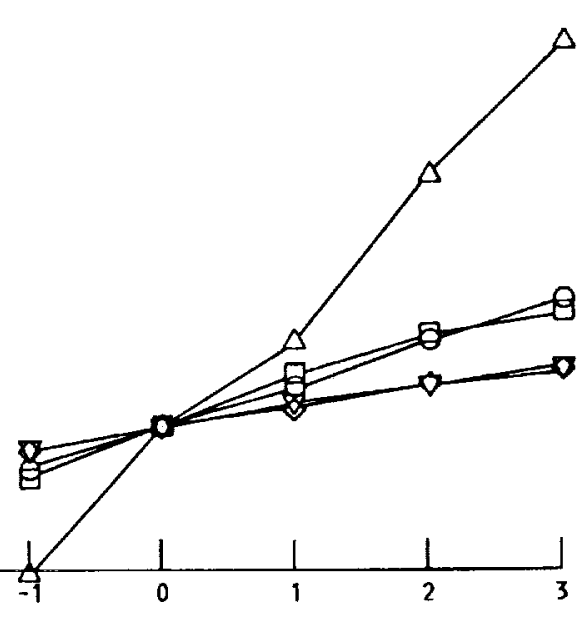

(b) SUCTION SURFACE.

FIGURE 8. - PRESSURE RESPONSE AS A FUNCTION OF INFIOW ANGLE AT $m_{\infty}=0.6$ AND J JEAS $=3.06$. 

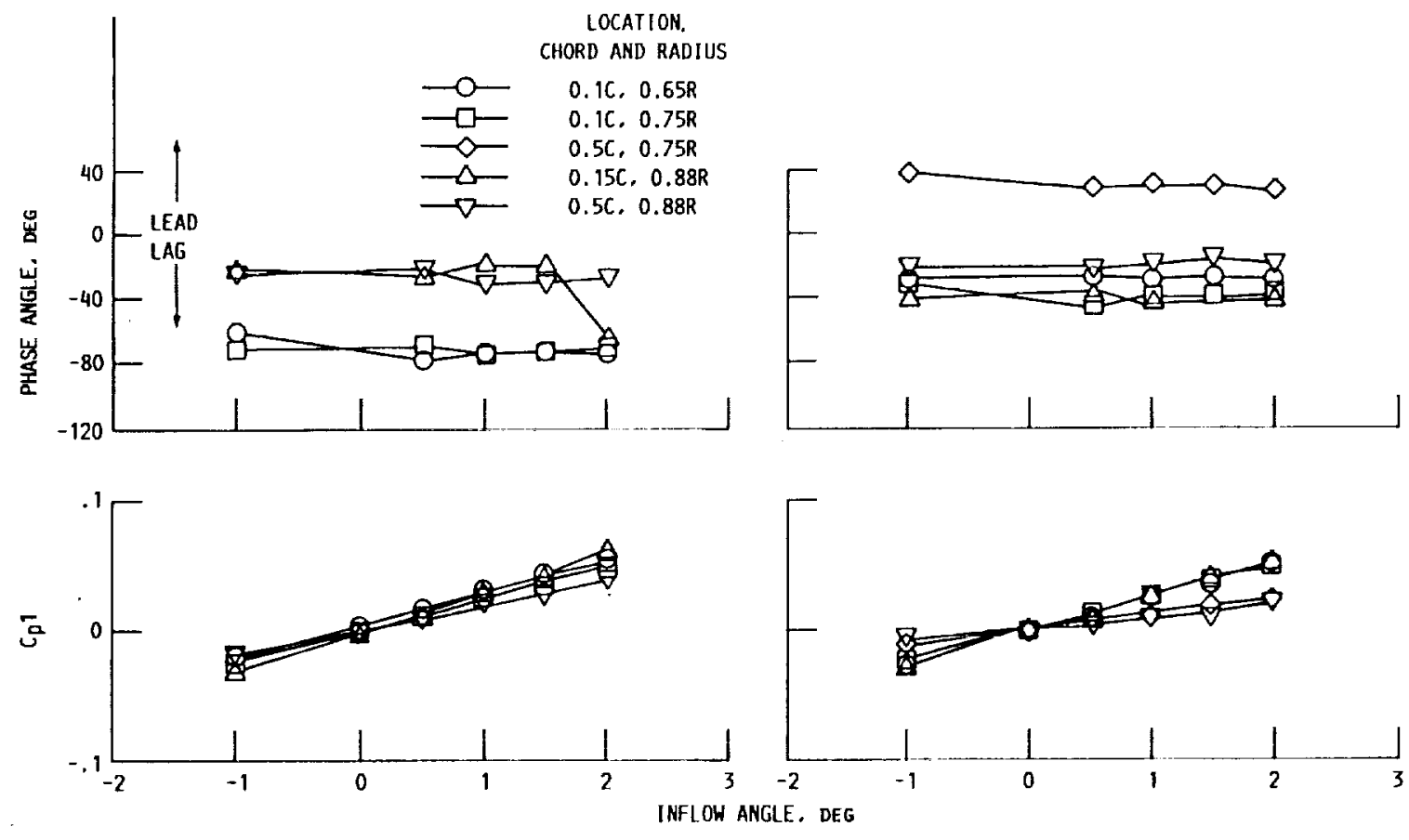

(a) PRESSURE SURFACE.

(b) SUCTION SURFACE.

FIGURE 9. - PRESSURE RESPONSE AS A FUNCTION OF INFLOW ANGLE AT $M_{\infty}=0.8$ AND J JEAS $=3.06$.
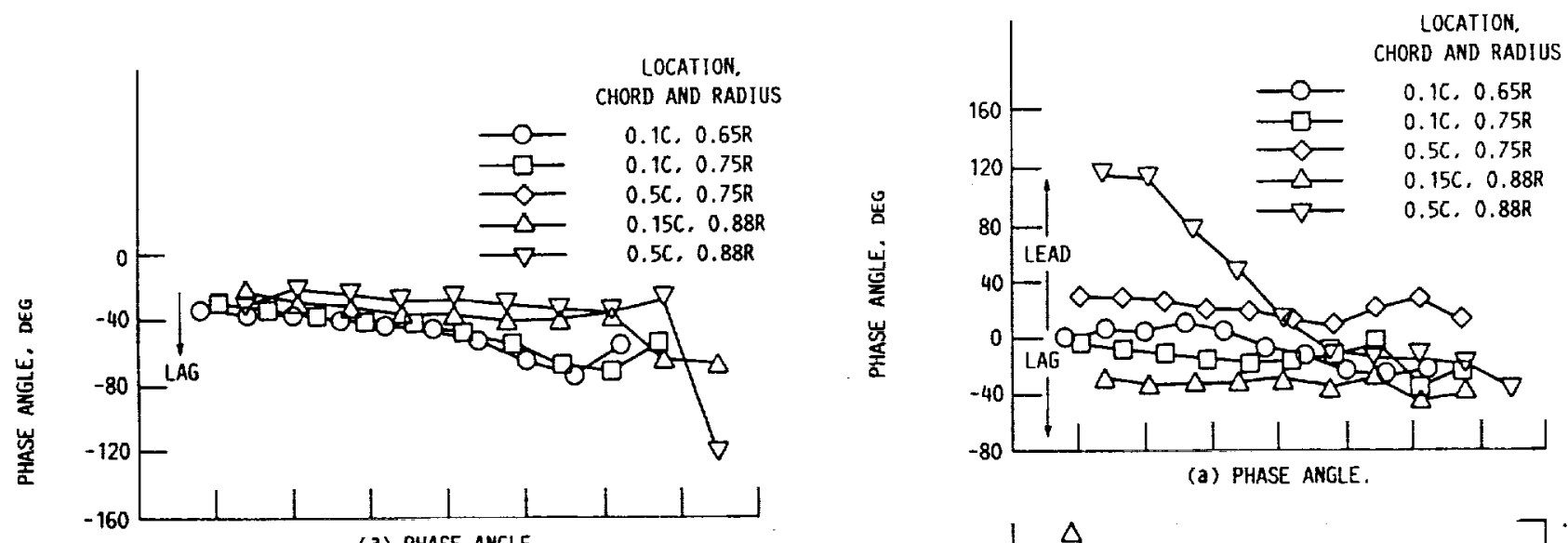

(a) PHASE ANGLE.
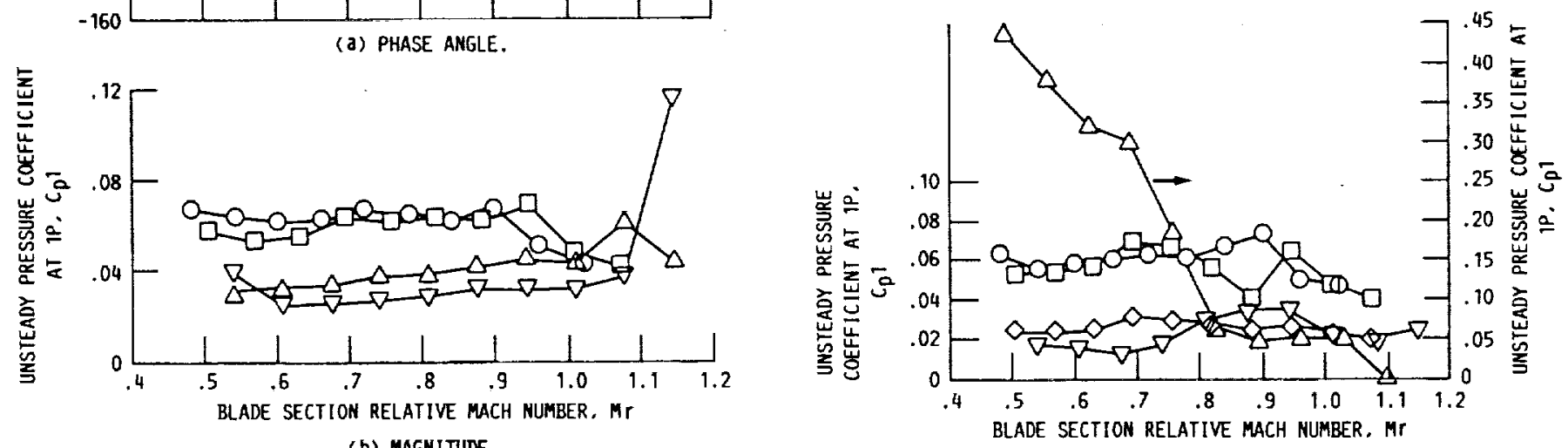

(b) MAGNITUDE.

FIGURE 10. - UNSTEADY PRESSURE COEFFICIENT AT THE FIRST SHAFT ORDER AS A FUMCTION OF BLADE SECTION RELATIVE MACH MUMBER. INFLOH ANGLE $=2^{\circ} ; \mathrm{J}=3.06$; PRESSURE SURFACE.

(b) MAGNITUDE.

FIGURE 11. - UNSTEADY PRESSURE COEFFICIENT AT THE FIRST SHAFT ORDER AS A FUNCTION OF BLADE SECTION RELATIVE MACH NUMBER, INFLOH ANGLE = $2^{\circ}, J=3.06$ SUCTION SURFACE. 

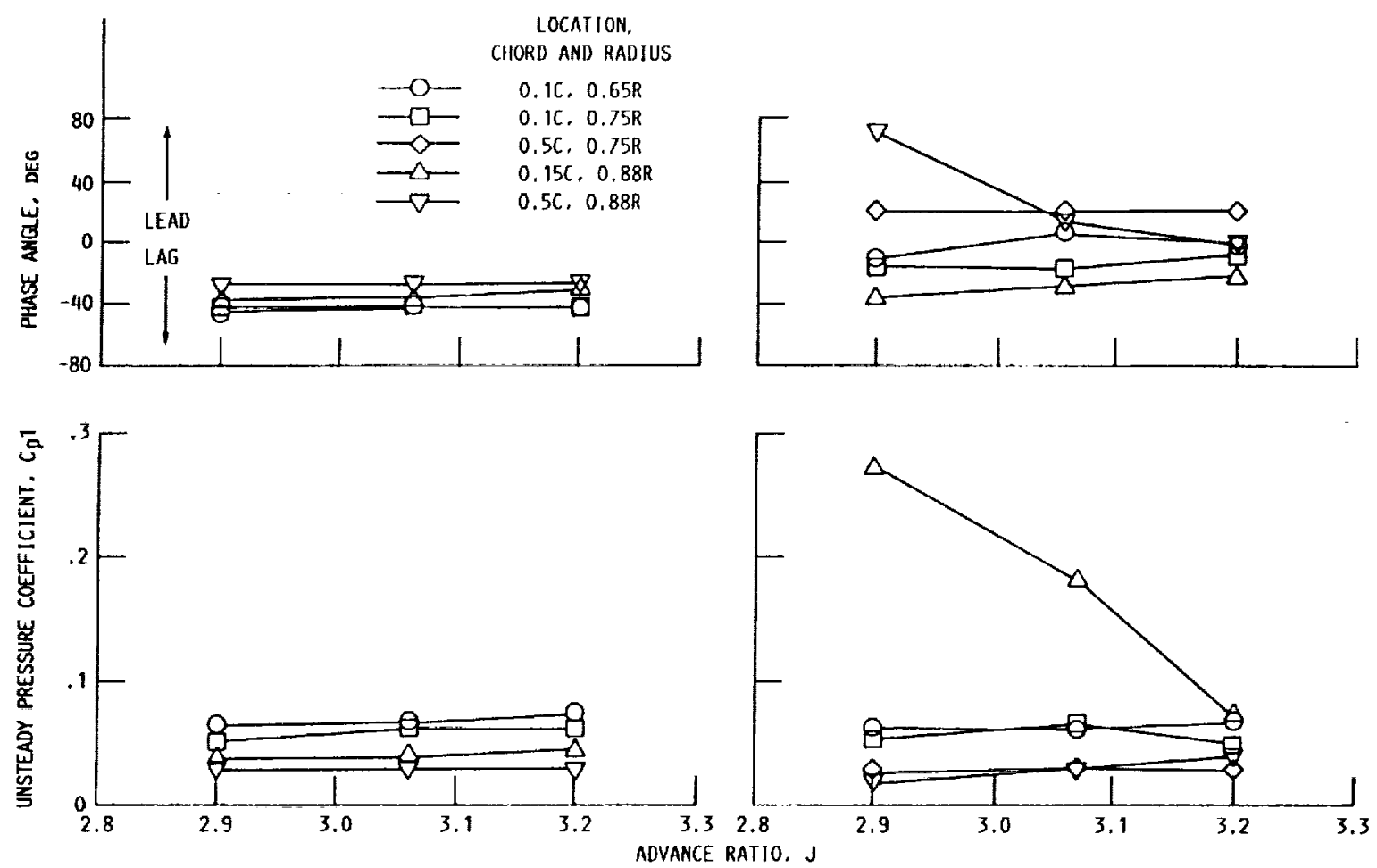

(a) PRESSURE SURFACE.

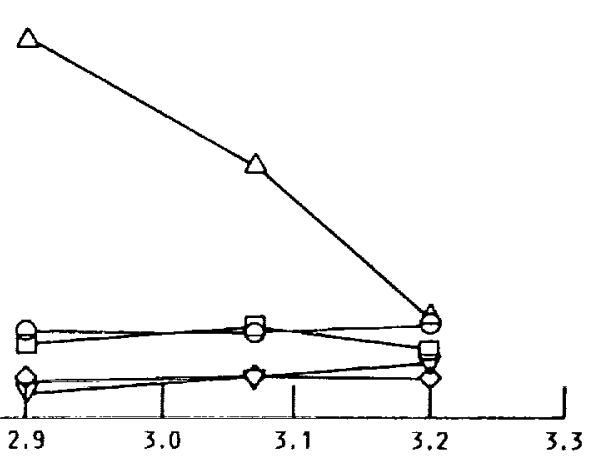

(b) SUCTION SURFACE.

FIGURE 12. - UNSTEADY PRESSIJRE COEFFICIENT AT THE FIRST SHWFT ORDER AS A FUNCTION OF ADVANCE RATIO AT MOO $=0.6$ AND $a=2.0^{\circ}$.
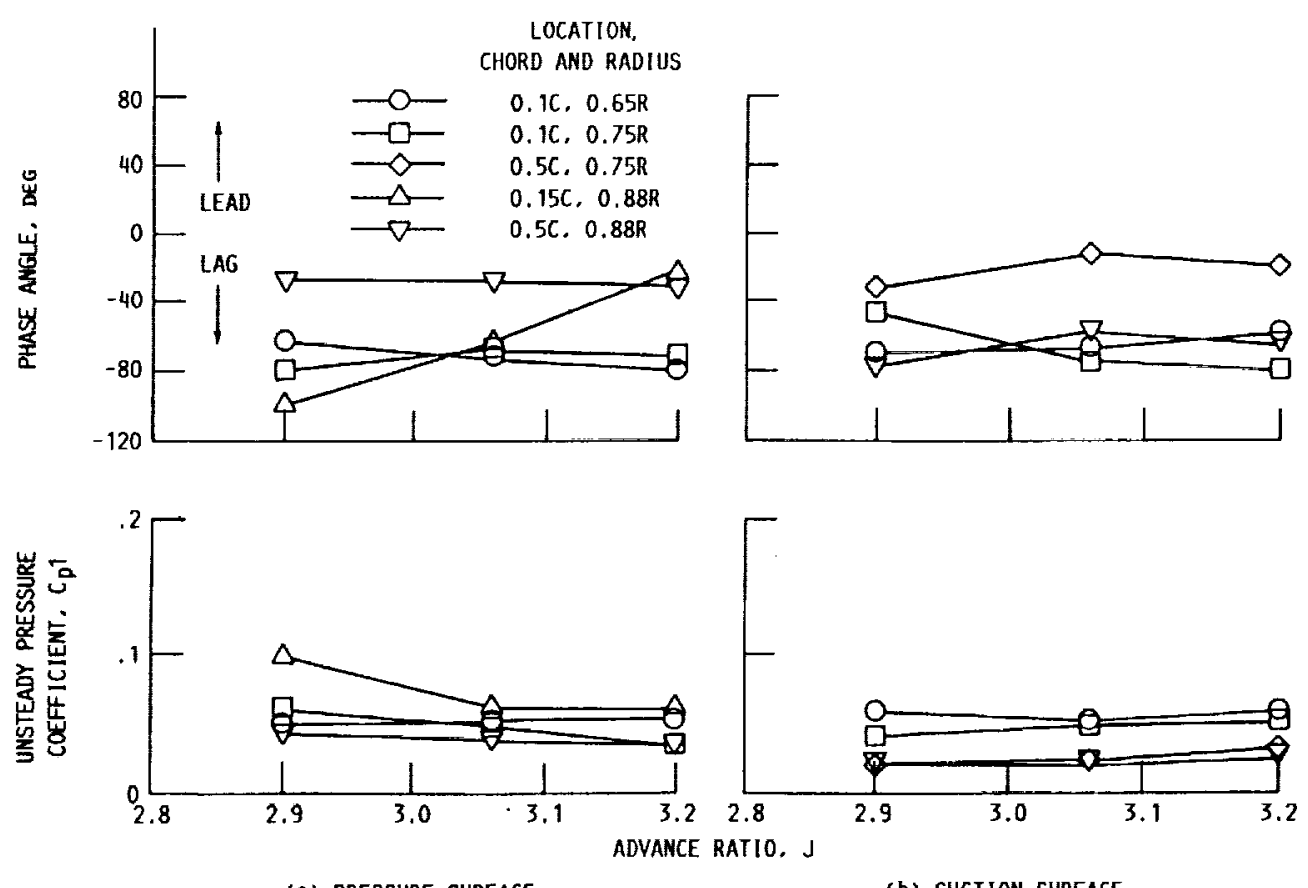

(a) PRESSURE SURFACE.

(b) SUCTION SURFACE.

FIGURE 13, - UNSTEADY PRESSURE COEFFICIENT AT THE FIRST SHAFT ORDER AS A FUNCTION OF ADVANCE RATIO AT $M_{\infty}=0.8$ AND $a=2.0^{\circ}$. 


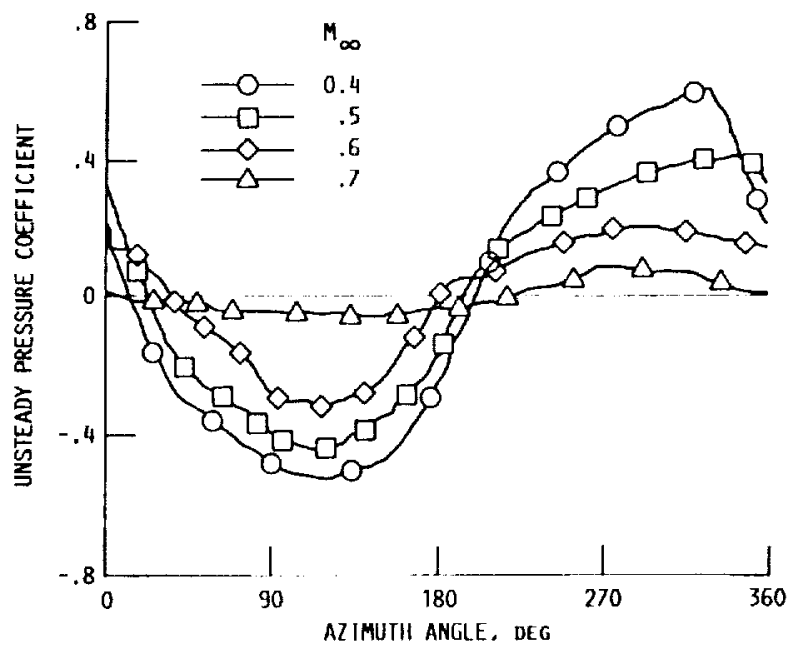

FIGURE 14. - WAVEFORMS FOR A LOCATION ON THE SUCTION SURFACE AT $0.15 C$ AND $0.88 R, a=2^{\circ}, J=3.06$.

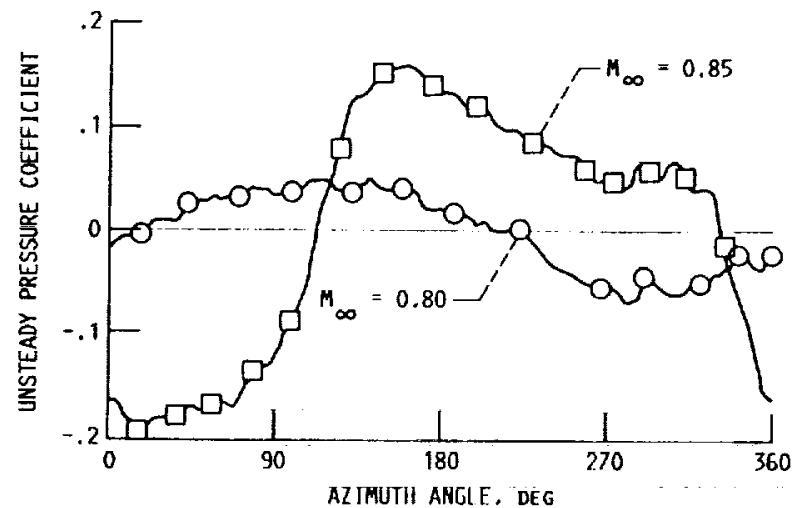

FIGURE 15. - WAVEFORMS FOR A LOCATION ON THE PRESSURE SURFACE AT $0.5 C$ AND $0.88 R, a=2^{0}, J=3.06$. 


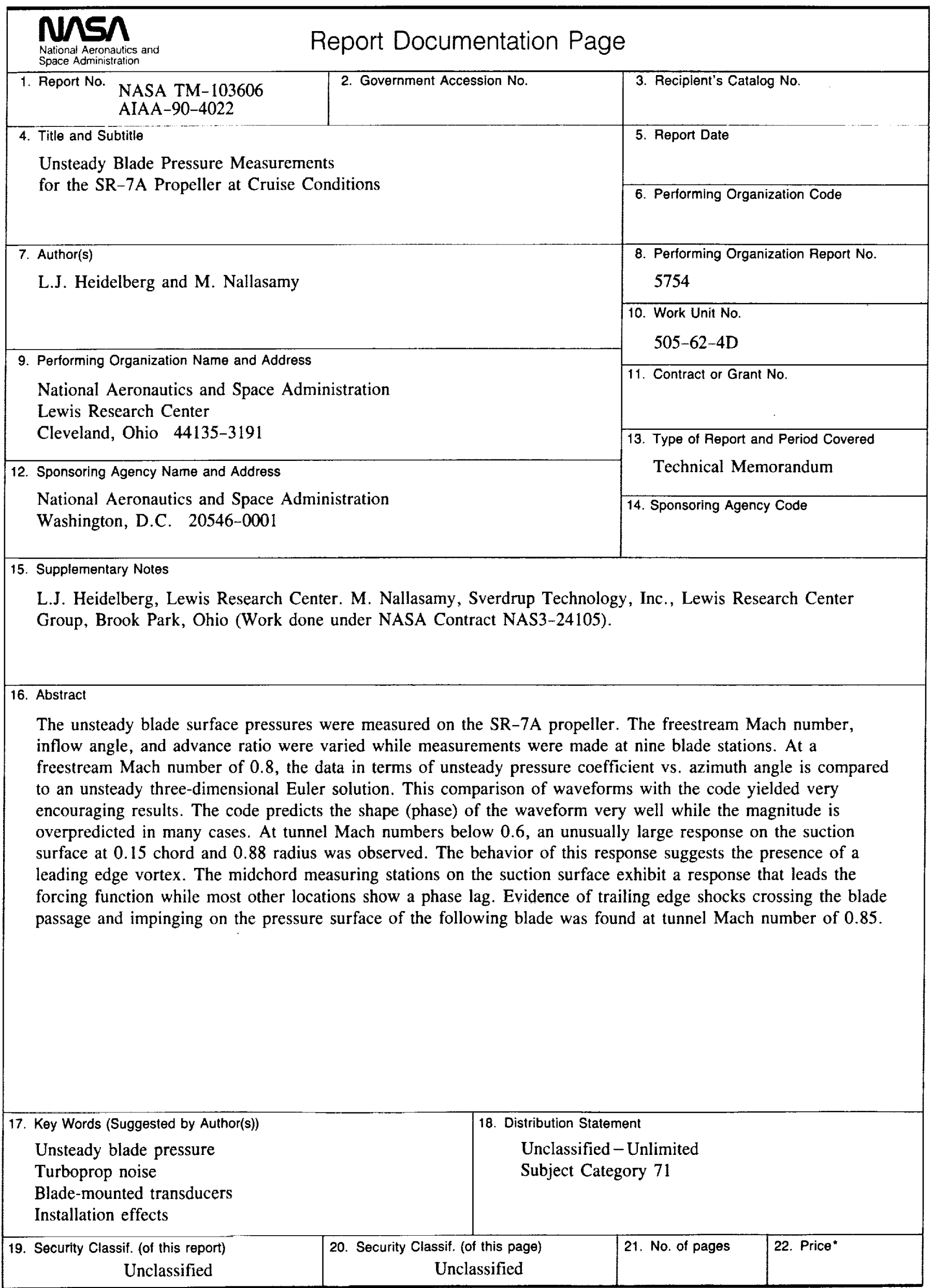

